\title{
Atomic Force Microscopy Imaging of Membrane Proteins
}

\author{
R.P. GonÇALVES*
}

Laboratory of Cell Biophysics, Ecole Polytechnique Federale de Lausanne, Switzerland

\begin{abstract}
Atomic force microscopy is a technique particularly adapted to the study of flat objects. The possibility to use it in an aqueous environment makes it a unique tool in biology, providing high resolution structural information of biological membranes. Here we will review atomic force microscopy advances in the study of membrane protein imaging, covering reconstituted proteins in lipid bilayers, native membranes and reviewing function-related imaging and its outcomes.
\end{abstract}

PACS numbers: 87.14.ep, 87.64.Dz

\section{Introduction}

Membrane proteins constitute a wide field of research. They only represent about $1 \%$ of protein structures published in the protein data bank, despite their importance in the world of biology, where they represent a rough average of $25 \%$ of all proteins produced by organisms. This shows how usual structural techniques, used for soluble proteins are not well adapted to the study of membrane proteins. This has led to the development of strategies to, for example, make 3D crystals of membrane for $\mathrm{X}$-ray studies or $2 \mathrm{D}$ crystals to be studied by electron microscopy and more particularly to the investigation of bilayers containing membrane proteins by atomic force microscopy (AFM). Like for St Thomas, many times in science seeing is believing and AFM [1] has allowed scientists in the last two decades to see in the nanoworld. The possibility to use AFM in biology is directly linked to its conception. This scanning probe technique allows working in aqueous conditions [2], similar to the living conditions of most living beings on earth, giving birth to a wide field of research of biological objects, including whole cells [3], DNA [4] and membrane proteins [5]. The high signal-to-noise ratio of AFM imaging allows visualization at the single molecule level. In best cases it has been possible to use AFM to obtain submolecular structural information on membrane proteins in reconstituted $2 \mathrm{D}$ crystals [6], in native $2 \mathrm{D}$ crystals $[7,8]$, in non-crystalline supramolecular organizations $[9]$ and in multi-protein supramolecular organizations $[8,10,11]$.

\section{AFM imaging of membrane proteins in reconstituted lipid bilayers}

Photosynthesis and particularly bacterial photosynthetic systems are widely studied and constitute a subject

\footnotetext{
* Correspondence should be addressed to R.P. Gonçalves, LCB Station 15, EPFL, Lausanne, Switzerland.

E-mail: rui.pedro@gmx.net
}

of choice for AFM imaging. The 3D structure of the light harvesting complex (LH2) of Rhodopseudomonas (Rps) acidophila [12] and Rhodospirillum (Rsp) molischianum [13] were amongst the first structures of membrane proteins to be published. The first one yielded a ninefold tertiary structure whereas the second one has eight subunits.

LH2 from Phaespirillum (Psp) molischianum can be reconstituted in lipid bilayers [14] that readily adsorb on the mica surface (Fig. 1a) and can be imaged by AFM. An overview (Fig. 1a) shows proteins protruding at different heights, indicating that the LH2 are inserted in the membrane with both orientations, sometimes with the cytoplasmic side facing up, and sometimes the opposite.

High-resolution imaging (Fig. 1b) shows complexes of different sizes, indicating a capacity of adaptation of bacteria to different conditions. Most complexes have a diameter of $5 \mathrm{~nm}$ corresponding well to the X-ray structure [13] and have eight subunits. Other complexes have diameters reaching $8 \mathrm{~nm}$ and have thirteen subunits (Fig. 1c). Different sized complexes mean broader absorption spectra. This adaptation at a molecular level, modifying tertiary structures of single proteins was first shown by AFM, as other averaging techniques, like X-ray crystallography and 2D electron microscopy "erase" the specificity of single molecules. The adaptation of the membrane protein to different light conditions during growth and the possibility to adopt a large variety of conformations has been shown in Psp photometricum [10,11], Rps palustris [15] and Allochromatium vinosum [16].

\section{AFM imaging of native membranes}

AFM imaging was also applied to study proteins in native membranes. These were not exposed to any detergent or submitted to freeze-thaw cycles, therefore letting the membrane proteins in a very close to native environment representing the supramolecular arrangement in cells $[8,9,11,17]$. Rsp molischianum membrane patches could be imaged at high resolution (Fig. 2a). In AFM to- 


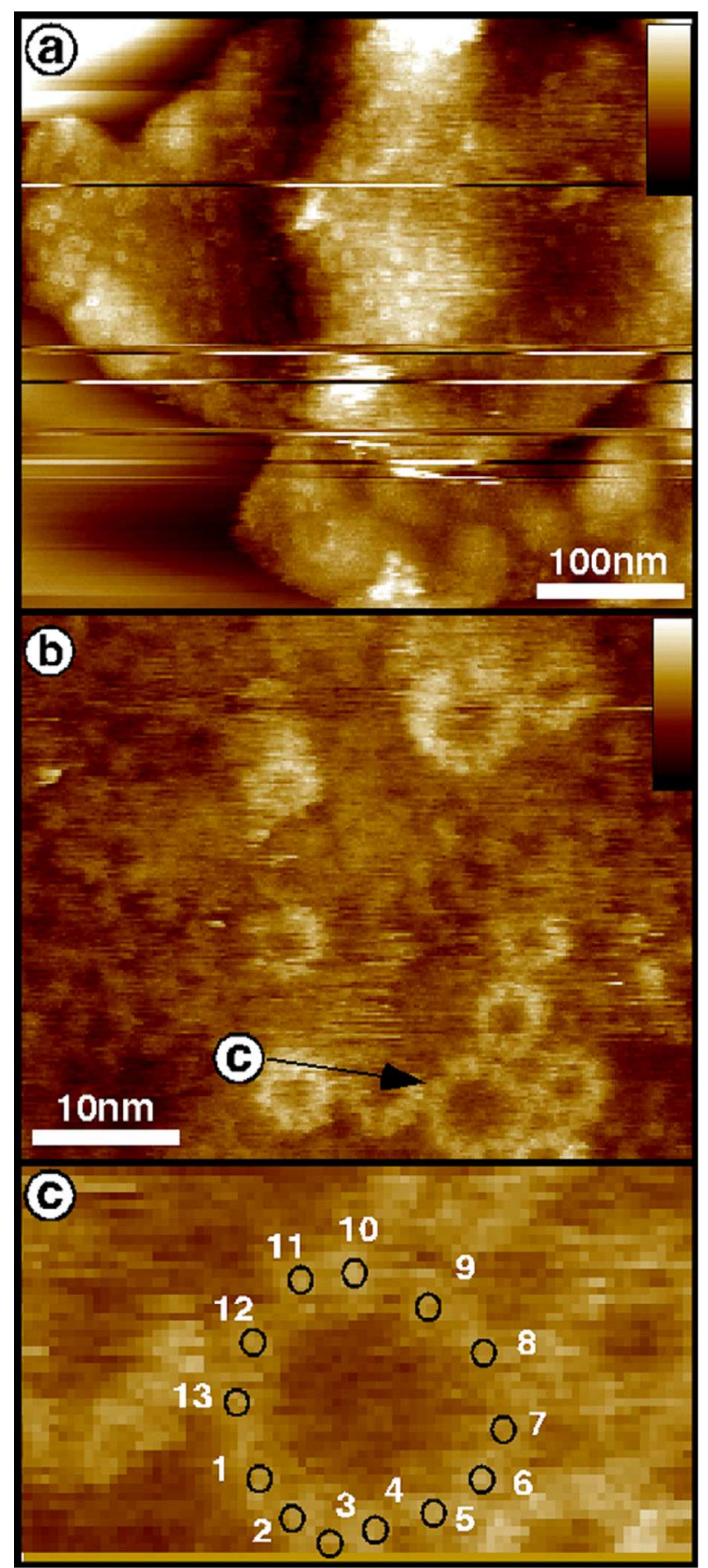

Fig. 1. AFM topograph of LH2 complexes of Psp photometricum. (a) Mid resolution height image of a reconstituted lipid bilayer containing LH2 complexes. Membrane height is $6.2 \mathrm{~nm}$. The protein is inserted in both orientations, as shown by different protruding heights from the proteins (color scale $5 \mathrm{~nm}$ ). (b) High-resolution topograph of a highly dense membrane patch. LH2 complexes of different heights and sizes can be differentiated. The number of subunits is evaluated to vary from eight to thirteen. (c) Numerical zoom on a large LH2 complex allowing the identification of thirteen subunits, each corresponding to a pair of two hydrophobic polypeptides. pographs of the photosynthetic complex, three proteins can be identified and studied. The LH2 complex is the smaller ring of $5 \mathrm{~nm}$ diameter, the LH1 complex is the larger ring, of $10 \mathrm{~nm}$ diameter and the reaction center is surrounded by the LH1 ring. These topographs bring information at several levels. At the supramolecular level, AFM is the only technique that allows visualization of the interactions of multiple proteins. For the photosynthetic system, it has allowed discovery of subunit variability for the LH2 complex, the study of LH1-LH1 and LH1-LH2 interactions and organization in the membrane, the adaptation of the membrane to different growth conditions at the molecular level, modelization of the supramolecular arrangements at atomic resolution and has given several clues on the role of cytochrome Bc1 complex and the whole functioning of photosynthesis in purple bacteria.

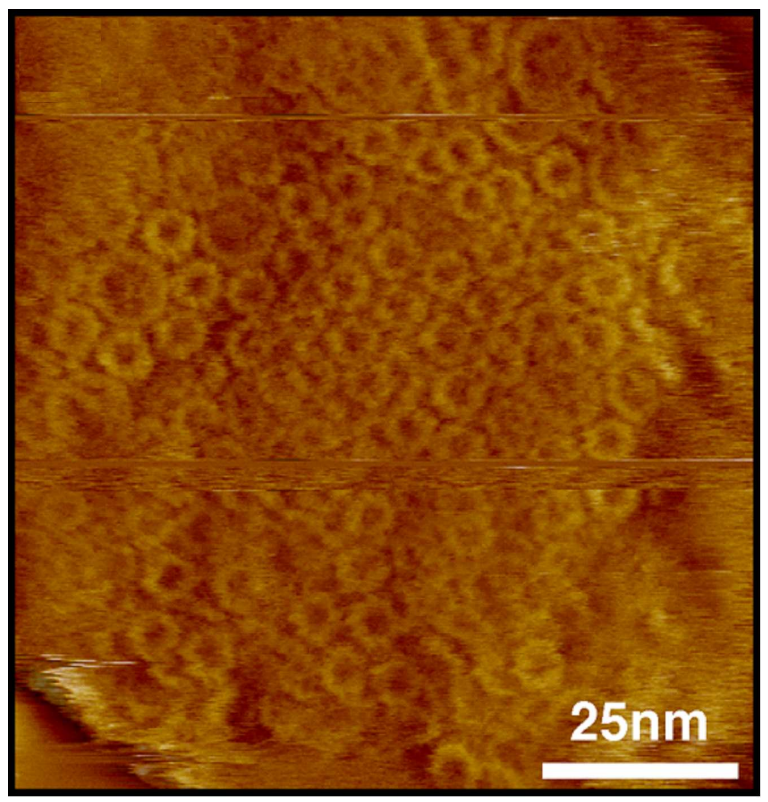

Fig. 2. AFM overview topograph of native Rsp molischianum chromatophores of core-complex containing membrane domains. A wide variety of complex assemblies is found. The majority of LH2 complexes favorably compare with an 8-fold LH2 average, some LH2 rings appear smaller with diameters $\approx 38 \AA$ or larger with diameters up to $57 \AA$. the reaction center is completely surrounded by elliptical LH1 assemblies with long and short axes of $95 \AA$ and $85 \AA$.

\section{Sample preparation}

There are not any universal rules for a good sample preparation in AFM, but some major guidelines. Firstly, to achieve high resolution, an ideal setup of the microscope is necessary. Software, hardware and environment of the AFM to reduce internal and external noise need to be prepared and monitored carefully. Extra vibration isolation equipment and a controled environment might be necessary to complement the usual AFM setup. 
Buffer composition used for preparation, adsorption and imaging of the samples are also of prime importance, along with their purity. As membrane proteins vary considerably in electronic environment and shape, the microscopist can act on ionic composition, $\mathrm{pH}$, adsorption time and sample concentration to find ideal conditions for imaging. An example of conditions that led to high resolution on Rsp molischianum [17] were $3 \mu \mathrm{l}$ of membrane solution injected into the $40 \mu \mathrm{l}$ adsorption buffer (10 mM Tris-HCl, pH 7.2, $150 \mathrm{mM} \mathrm{KCl,} 25 \mathrm{mM} \mathrm{MgCl}_{2}$ ). After $\approx 1 \mathrm{~h}$ the sample was rinsed with recording buffer (10 mM Tris- $\mathrm{HCl}, \mathrm{pH} 7.2,150 \mathrm{mM} \mathrm{KCl}$ ). Imaging was performed with a commercial Nanoscope-E AFM (Veeco, Santa Barbara, CA, USA) equipped with a $160 \mu \mathrm{m}$ scanner (J-scanner) and oxide-sharpened $\mathrm{Si}_{3} \mathrm{~N}_{4}$ cantilevers (length $100 \mu \mathrm{m} ; k=0.09 \mathrm{~N} / \mathrm{m}$; Olympus Ltd., Tokyo, Japan). High resolution AFM can be obtained with different microscopes, in contact and intermittent contact modes and with several, usually sharpened, tips, but this kind of setup has regularly been used and produced good results.

\section{Outcomes in function-related imaging by AFM}

The final purpose of structural studies of membrane proteins is to understand their function. However, proteins are dynamic objects that change conformation throughout their action. Therefore the structure alone, in a fixed conformation is sometimes not enough to fully comprehend the action of a protein. New developments in AFM try to tackle these questions by enhancing the microscope's capacities or combining it with other apparatus. A first approach was to use different kinds of supports for the cells and membranes to perform force spectroscopy [18] and functional studies by fluorescence microscopy [19]. Performing AFM on holey supports, allowed membranes to be unsupported [20]. These membranes are then separating two aqueous compartments, as is the case for membranes in live cells, which separate the cytoplasm from the extracellular environment. This setup allows the control and the establishment of gradients across the unsupported membranes, mimicking the mechanisms that drive protein function. Membrane gradients activate many membrane proteins that work as channels, pumps, receptors, in signal transduction, in metabolic and bioenergetics processes.

S-layer membranes of Corynebacterium glutamicum successfully adsorb to holey Si support using buffers containing divalent ions [20]. A flatly adsorbed membrane with dimensions in the micrometer range completely covers wells of $80 \mathrm{~nm}$ diameter (Fig. 3a). By adapting scanning parameters it is possible to reach molecular resolutions (Fig. 3b) and the best resolutions obtained are estimated at $15 \AA[20]$. Further developed, this setup will allow study of functional aspects, observing conformational changes of membrane proteins due to ion-, $\mathrm{pH}-$, or solute-gradients, cargo transport, force-induced alter- ations of mechano-sensible membrane proteins, and measuring membrane diffusion or inter- and intra-molecular forces.

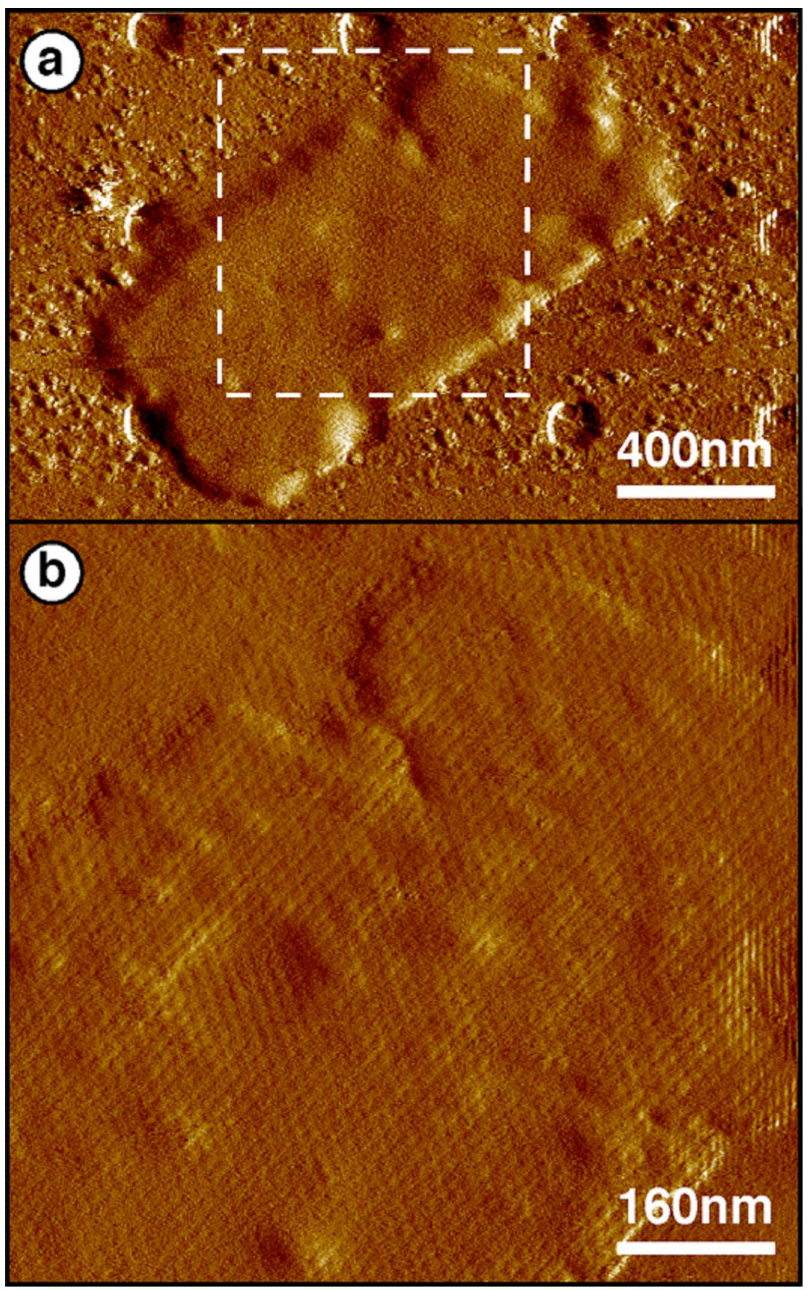

Fig. 3. AFM imaging of unsupported Corynebacterium glutamicum S-layer membranes. (a) Overview topograph of S-layers adsorbed to the holey $\mathrm{Si}(001)$ AFM support. The membrane covers several wells. (b) Topograph of the S-layer outlined in (a). Deflection image reveals the hexagonal crystalline packing of the S-layer proteins.

Other developments in the field aim at combining AFM with optical microscopes. These systems allow simultaneous acquisition of the AFM signal and an optical image [21]. These systems promise bright outcomes, being applied in the fields of cancer research [22], cell adhesion [23], actin skeleton structure [24] and protein recognition [21]. In addition, several laboratories are developing high speed AFMs that produce images at "video" speed, higher than 25 frames per second. These give access to dynamic biomolecular processes that cannot be visualized by classical AFM [25]. 


\section{References}

[1] G. Binnig, C.F. Quate, C. Gerber, Phys. Rev. Lett. 56, 930 (1986).

[2] B. Drake, C.B. Prater, A.L. Weisenhorn, S.A.C. Gould, T.R. Albrecht, C.F. Quate, D.S. Cannell, H.G. Hansma, P.K. Hansma, Science 243, 1586 (1989).

[3] Y.F. Dufręne, Micron 32, 153 (2001).

[4] H.G. Hansma, D.E. Laney, M. Bezanilla, R.L. Sinsheimer, P.K. Hansma, Biophys. J. 68, 1672 (1995).

[5] F.A. Schabert, C. Henn, A. Engel, Science 268, 92 (1995).

[6] F. Schabert, J.H. Hoh, S. Karrasch, A. Hefti, A. Engel, J. Vac. Sci. Technol. B 12, 1504 (1994).

[7] D.J. Müller, F.A. Schabert, G. Büldt, A. Engel, Biophys. J. 68, 1681 (1995).

[8] N. Buzhynskyy, R.K. Hite, T. Walz, S. Scheuring, Embo Rep. 8, 51 (2007).

[9] R.P. Gonçalves, N. Buzhynskyy, V. Prima, J.N. Sturgis, S. Scheuring, J. Mol. Biol. 369, 413 (2007).

[10] S. Scheuring, J.N. Sturgis, Science 309, 484 (2005).

[11] S. Scheuring, J.-L. Rigaud, J.N. Sturgis, EMBO J. 23, 4127 (2004).

[12] G. McDermott, S.M. Prince, A.A. Freer, A.M. Hawthornthwaite-Lawless, M.Z. Papiz, R.J. Cogdell, N.W. Isaacs, Nature 374, 517 (1995).

[13] J. Koepke, X. Hu, C. Muenke, K. Schulten, H. Michel, Structure 4, 581 (1996).
[14] M. Chami, G. Pehau-Arnaudet, O. Lambert, J. Ranck, D. Lévy, J. Rigaud, J. Struct. Biol. 133 , 64 (2001).

[15] S. Scheuring, R.P. Gonçalves, V. Prima, J.N. Sturgis, J. Mol. Biol. 358, 83 (2006).

[16] S. Kereïche, L. Bourinet, W.A. Keegstra, A.A. Arteni, J.-M. Verbavatz, E.J. Boekema, B. Robert, A. Gall, FEBS Lett. 582, 3650 (2008).

[17] R.P. Gonçalves, A. Bernadac, J.N. Sturgis, S. Scheuring, J. Struct. Biol. 152, 221 (2005).

[18] X. Yao, M.H. Jericho, D. Pink, T.J. Beveridge, J. Bacteriol. 181, 6865 (1999).

[19] C. Danelon, J.P. Perez, C. Santschi, J. Brugger, H. Vogel, Langmuir 22, 22 (2006).

[20] R.P. Gonçalves, G. Agnus, P. Sens, C. Houssin, B. Bartenlian, S. Scheuring, Nat. Meth. 3, 1007 (2006).

[21] B.H. Lower, R. Yongsunthon, L. Shi, L. Wildling, H.J. Gruber, N.S. Wigginton, C.L. Reardon, G.E. Pinchuk, T.C. Droubay, J.F. Boily, S.K. Lower, Appl. Environ. Microbiol. 75, 2931 (2009).

[22] M. Lekka, P. Laidler, D. Gil, J. Lekki, Z. Stachura, A.Z. Hrynkiewicz, Europ. Biophys. J. 28, 312 (1999).

[23] P. Pittet, A. Kulik, L. Kyumin, J.-J. Meister, B. Hinz, J. Cell Sci. 121, 877 (2008).

[24] Z. Deng, T. Zink, H.Y. Chen, D. Walters, F.T. Liu, G.Y. Liu, Biophys J. 96, 1629 (2009).

[25] M. Yokokawa, C. Wada, T. Ando, N. Sakai, A. Yagi, S. Yoshimura, K. Takeyasu, EMBO J. 25, 4567 (2006); H. Yamashita, K. Voïtchovsky, T. Uchihashi, S.A. Contera, J.F. Ryan, T. Ando, J. Struct. Biol., Epub ahead of print May 3 (2009), 167, 153 (2009). 